\title{
2084
}

ELSEVIER

\section{Regulation of Immune Reactivity and Tolerance by Antigen Migration and Localization: With Particular Reference to Allo- and Xenotransplantation}

\author{
T.E. Starzl, N. Murase, A.W. Thomson, M. Trucco, and A. Rao
}

$\mathrm{T}$ HE SPECIFIC immunologic non-reactivity to allografts that was first produced in fetal or neonatal mice by Billingham, Brent, and Medawar, ${ }^{1}$ and, ultimately, in human bone marrow recipients ${ }^{2-5}$ has remained enigmatic for nearly a half century. Without first understanding this "acquired tolerance," and. especially, the "acceptance" of organ allografts it is folly to dream of a future that includes xenotransplantation.

Beginning in $1992{ }^{6}$ we have developed an explanation for successful transplantation of allografts that, if valid, could guide investigators directly to the objective of clinical xenotransplantation. A central tenet of our proposal is that immune reactivity or non-reactivity (tolerance) to transplanted tissues and organs, to microorganisms, and to all other antigens (including self), is governed by the migration and localization of the antigen. ${ }^{7}$ Evidence supporting the latter conclusion has been obtained from investigations of the previously unsuspected chimerism that occurs after organ transplantation ${ }^{6,8,9}$ and from observations following experimental and clinical infections. ${ }^{10-12}$

\section{THE MICROCHIMERISM DISCOVERIES}

In 1992, sparse but widely distributed multilineage donor leukocytes (microchimerism) were found in the blood or tissues of 30 of 30 human kidney and liver recipients whose allografts had functioned for as long as 30 years posttransplantation. $^{6,8.9 .13}$ Because committed leukocytes have a limited life span, this could only mean that precursor or stem cells are included in the burst of donor leukocytes that is briefly detectable in recipient blood following organ transplantation. ${ }^{8}$

In human liver and intestinal recipients the donor contribution to the circulating host white blood cells peaks at $10 \%$ to $20 \%$ after about 10 days, at the same time as these "passenger leukocytes" disappear from the graft. ${ }^{14.15}$ The same thing on a smaller scale is seen after transplantation of organs like the kidney and heart that contain fewer leukocytes.

These discoveries suggested an explanation for 2 enigmatic observations made 30 years earlier upon which the development of clinical organ transplantation at a practical level was based. In patients treated with azathioprine plus dose maneuverable prednisone, it had been found in 1962 to 1963 , first, that kidney rejection was a consistently reversible phenomenon, and, second, that renal allografts could systematically self-induce variable degrees of donor specific tolerance. ${ }^{16}$ It was soon learned that the same thing happened with other transplanted organs ${ }^{17}$, and could be observed in many animal models without the need for immunosuppression (summarized in Starzl et $\mathrm{al}^{18}$ ).

\section{THE HISTORICAL LINKAGE TO INFECTION}

Early workers in transplantation had recognized the resemblance of allograft rejection to the response against infections, such as tuberculosis, that were associated with delayed hypersensitivity. ${ }^{19}$ With the demonstration of the MHC-restricted mechanisms of adaptive infectious immunity by Zinkernagel and Doherty in 1973 and $1974,,^{20,21}$ it seemed obvious that allograft rejection must be analogous to the immune response to this kind of infection.

Typically, the microorganisms that generate an adaptive immune response are intracellular with low or no cytopathic qualities. Host cytolytic $\mathrm{T}$ lymphocytes recognize as targets only those cells displaying host MHC antigen plus relevant peptide of the infectious agent. However, because elimination of all the infected cells could disable or even kill the host, mechanisms have evolved that can temper or terminate the immune response, allowing both host and pathogen to survive.

After infection with widely disseminated non-cytopathic microorganisms (eg, the common hepatitis viruses), the antigen load rapidly increases in the so-called latent period (Fig 1, second panel). The delayed development and subsidence of effector $T$ cells, usually results in efficient, although rarely, if ever, complete, elimination of the patho-

From the Thomas E. Starzl Transplantation Institute and the Departments of Surgery (T.E.S., N.M., A.W.T., A.R.), and Pediatrics (M.T.), University of Pittsburgh Medical Center, Pittsburgh, Pennsylvania.

Aided by Project Grant No. DK 29961 from the National Institutes of Health, Bethesda, Maryland.

Address reprint requests to Thomas E. Starzl, MD, PhD, Department of Surgery, 3601 Fifth Avenue, 5C Falk Clinic, University of Pittsburgh, Pittsburgh, Pennsylvania, 15213. 
Fig 1. Potential outcomes after infection with noncytopathic microorganisms and analogies (expressed as rejection or graftversus-host disease) to organ and bone marrow transplantation. The horizontal axis denotes time. The vertical axis shows the magnitude of the viral load $(v$, solid line), and the host immune response (IR, dashed line). (By permission of New England Journal of Medicine, 339:1905, 1998)

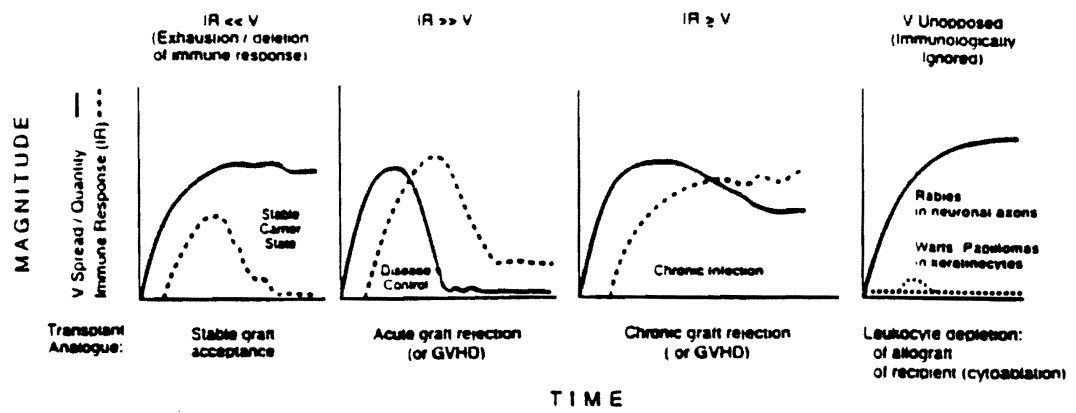

gen (Fig 1, second panel). These events are similar to those of irreversible rejection in the unmodified or ineffectively treated organ recipient.

Alternatively, however, such infections may lead to a continuously high antigen load and to an antigen specific immunologic collapse, resulting in an asymptomatic carrier state (Fig 1, left panel). This is equivalent to unqualified acceptance of an allograft.

Between these 2 extremes leading to a carrier state (left panel) and protective immunity (second panel), an unrelenting immune response (dashed line) to a persistent infectious agent as shown in Fig 1 third panel can result in serious immunopathology (eg, chronic active hepatitis caused by a $\mathrm{B}$ or $\mathrm{C}$ virus infection). By analogy, this is equivalent to chronic rejection, or uncommonly GVHD after liver transplantation (see later).

\section{MECHANISMS OF NON-REACTIVITY}

The biologic safety valve that permits the compromise outcomes in the first and third panels of Fig 1 consists of only 2 mechanisms, both regulated by antigen migration and localization. ${ }^{7}$ One mechanism is clonal exhaustion leading to clonal deletion. The other is immune indifference.

\section{CLONAL EXHAUSTION/DELETION}

Thirty years ago, we postulated that the fundamental mechanism of organ engraftment under immunosuppression was proliferative exhaustion and deletion of a donor specific clone, 22 and cited an even earlier prediction by Schwartz and Dameshek ${ }^{23}$ that this might occur. Clonal exhaustion was generally discounted. however, in part because it remained only a theoretical possibility until its experimental verification by Webb, Morris, and Sprent in $1990 .{ }^{24}$ Since then. clonal exhaustion has been demonstrated in many infectious, transplantation, and other models as recently summarized by Bishop et al. ${ }^{25}$

In these diverse models, a subpopulation of $T$ cells is induced by the antigen within a few days. end differentiates to effector cells. and disappears. Death of the activated cells by interleukin deprivation and other mechanisms associated with apoptosis seem to be involved. ${ }^{20.27}$ Although this purging is thymus dependent in many mammalian species, deletion also occurs in the peripheral lymphoid organs, ${ }^{28}$ which may be the principal if not the sole sites in human organ recipients. ${ }^{18}$

Clonal exhaustion as the primary mechanism of organ allograft acceptance was ignored in the literature for more than 2 decades beginning in 1970 because of failure to understand the role of the organ's passenger leukocytes. These donor cells of bone marrow origin have long been known to be the principal immunogenic component of allografts, ${ }^{29.30}$ a quality widely attributed to their expression of major histocompatibility complex class II and/or costimulatory molecules. ${ }^{31}$ Consequently, the disappearance of passenger leukocytes from long surviving transplanted tissues and organs was assumed, first, to be an obligatory condition for allograft acceptance, and, second, to connote the selective destruction of these donor cells by the recipient immune system with selective sparing of the specialized parenchymal ceils.

With the latter disorienting premise, organ allograft acceptance appeared to be different than the chimerismdependent acquired neonatal tolerance of Billingham. Brent, and Medawar ${ }^{1}$ and its clinical analogue, bone marrow transplantation..$^{-5}$ Consequently, numerous chimerismexclusionary hypotheses for organ allograft acceptance sprang up involving immune regulatory cells, cytokine profile changes, and various antibody states. ${ }^{7} \mathrm{~A}$ popular current theory is that $\mathrm{T}$ cells, both in lymphoid organs and in the periphery, are turned-off ("anergized") if they encounter appropriately presented antigen in the absence of a second signal provided by costimulatory (B7) molecules.

Contrary to these hypotheses, the discovery of microchimerism in organ recipients, has made it possible to explain allograft acceptance by ". . . [widespread] responses of coexisting donor and recipient immune cells, each to the other. causing reciprocal clonal expansion. followed by peripheral clonal deletion [clonal exhaustion]." " If some degree of reciprocal clonal exhaustion is not induced and maintained. one cell population will destroy the other, or hoth may he destroved together. ${ }^{0-4.1 x}$

Following organ transplantation, the dominant host system (Fig 2) usually rejects the graft, but serious or lethal GVHD is not rare after transplantation of leukocyte-rich 


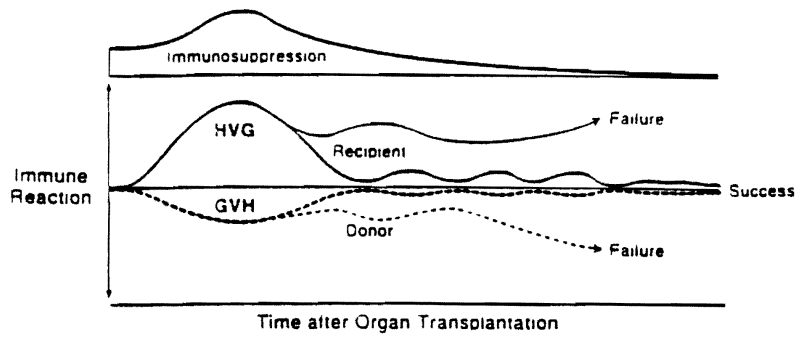

Fig 2. Contemporaneous host-versus-graft (HVG) and graftversus-host $(\mathrm{GVH})$ reactions after transplantation. Failure is defined as the inability to control one of the reactions, or sometimes both. Acute reciprocal clonal exhaustion after successful transplantation is maintained subsequently by chimerism-dependent low-grade stimulation of both leukocyte populations that may wax and wane. (By permission of New England Journal of Medicine, 339:1905, 1998)

organs like the liver. ${ }^{8}$ In contrast, weakening of host immune reactivity by cytoablation prior to bone marrow transplantation transfers dominance to the donor system. Consequently, GVHD is the most common complication in bone marrow recipients, but the graft may be rejected instead, or simultaneously. ${ }^{6-8.18}$

"What governs clonal exhaustion?" It is well known that immune activation against spreading non-cytopathic pathogens requires their migration to and localization in lymphoid organs. ${ }^{10,11}$ The similar lymphoid-oriented traffic of passenger leukocytes has been well documented..$^{32-34}$ It is self evident that this pattern of antigen migration, which is the essential basis of host sensitization, also is the prerequisite for specific immunologic tolerance by clonal exhaustion.

\section{IMMUNE INDIFFERENCE}

However, survival of the antigen may be enhanced by a second non-tolerogenic mechanism, called "immune indifference." 7.10-12 Like clonal exhaustion, immune indifference also is controlled by antigen migration and localization.

Primary Immune Indifference. Pure examples of immune indifference are provided by the rabies and wart viruses (Fig 1. right panel) that elicit little or no immune response by avoiding migration through, or to, host lymphoid organs. This situation has been mimicked in many transplant models by depletion of donor leukocytes trom allografts. ${ }^{35.36}$ Although allograft survival is thereby prolonged, donor specific tolerance does not develop. Rejection can be readily precipitated with an injection of donor leukocytes $^{35.36}$ as first shown 30 years ago by Elkins and Guttman. ${ }^{30}$

Secondary Immune Indifference. Such de novo nonresponsiveness is not seen in the usual setting of clinical organ transplantation, but it may evolve secondarily. ${ }^{-x}$ As also occurs following a widespread nuncytopathic infection. ${ }^{2}$ migratory donor leukocytes that have not been eliminated by passage through lymphoid organs leave the lymphoid compartment after about 2 weeks, having induced various stages of antigen specific exhaustion that is probably almost never complete or absolutely irreversible.

In animal models, and also in humans, the principal donor leukocyte population has secondarily migrated by 100 days posttransplantation to nonlymphoid sites, such as skin and heart (Fig 3), making it increasingly difficult to detect microchimerism in random blood samples or in biopsies of lymphoid organs. In the meanwhile, the leukocyte-depleted organ allograft becomes progressively less immunogenic. Maintenance clonal exhaustion apparently occurs subsequently by leakage of donor leukocytes from the non-lymphoid to the lymphoid compartment (Fig 3). ${ }^{7}$

Although the consequent balance between antigraft immunity and clonal exhaustion has been difficult to quantify in transplantation models, it has been demonstrated by Ohashi and Zinkernagel in transgenic mice whose pancreatic islets express viral antigens and are destroyed (with resulting diabetes) by the induction of high, but not by low level, virus specific CTL activity. ${ }^{37.38}$

\section{THE COLLABORATION OF MECHANISMS}

Organ Transplantation. With clonal exhaustion and immune indifference in combination, both regulated by the migration and localization of antigen, 4 inter-related events must occur close together if organ transplantation is to succeed: ${ }^{6-8}$ clonal exhaustion of the recipient antidonor immune response, reciprocal deletion of the donor immunocyte population, maintenance clonal deletion, and loss of

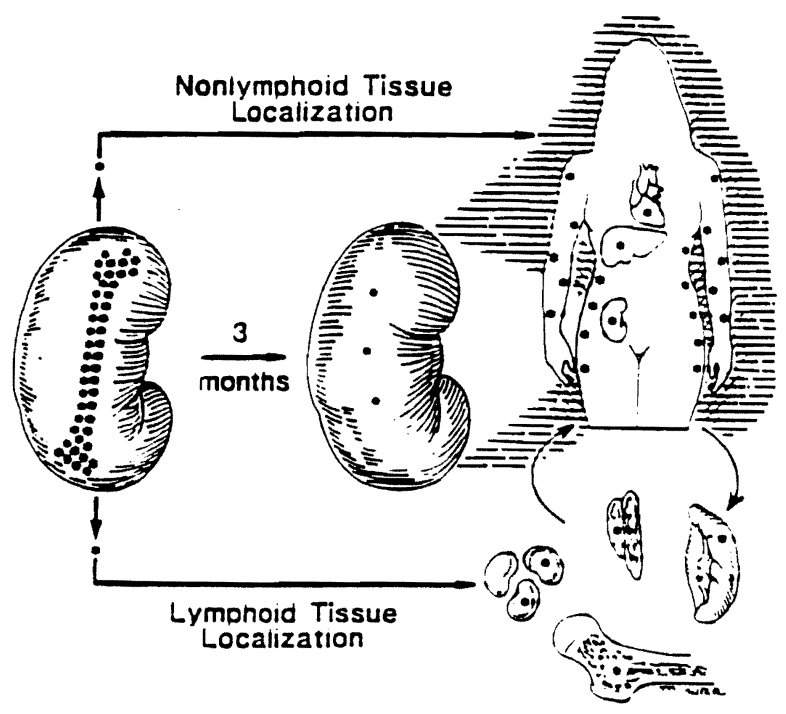

Fig 3. The distribution of donor leukocytes (") 3 months after organ transplantation (here, a kidney). With the nearly complete departure from the allograft of these cells reducing the organ's immunogenicity, they are replaced by recipient leukocytes. Note the eventual dominance of chimerism in the non-lymphoid organs (skin, heart, and liver shown), and the communication between the non-lymphoid and lymphoid (spleen, thymus, lymph nodes. and bone marrow) compartments. 
Table 1. Effectors Involved in Response to Cytopathic Parasites and Discordant Xenografts

\begin{tabular}{l}
\hline \multicolumn{1}{c}{ The First Line of Defense } \\
\hline 1. Interferons \\
2. Macrophages \\
3. $\gamma / \delta T$ cells \\
4. Natural killer (NK) cells \\
5. B cells Non-Specific or Less Specific Effectors \\
1. Complement \\
2. Early interleukins \\
3. Phagocytes
\end{tabular}

organ immunogenicity by in situ passenger leukocyte depletion.

Donor leukocyte chimerism is critical to these events. However, the significance of microchimerism following organ transplantation has been questioned (summarized in Woods and Sachs ${ }^{39}$ ) because, as we have emphasized $^{6-8.18 .40}$ donor leukocytes may be detectable during rejection, are often not detectable in individual blood or tissue samples in patients bearing stable allografts, and cannot, therefore, be used to guide drug weaning. These observations are readily fitted into the concept of various balanced states that may vary with time and according to antigen migration and localization. As we concluded in our 1992 Lancet report, ${ }^{6}$ and, again, recently " ... donor leukocyte chimerism is a prerequisite for, but neither synonymous with nor a consequence of, the evolution of organ allograft acceptance under clinically relevant circumstances."7

Bone Marrow Transplantation. Conventional bone marrow transplantation is, not only a mirror image of the events after organ transplantation, ${ }^{18.41}$ but also governed by antigen migration and localization. ${ }^{7}$ Although pretransplant cytoablation renders the recipient subject to GVHD. the host leukocytes are not all eliminated. The weak host versus graft reaction mounted by those recipient cells that remain, and by the parallel GVH reaction of the donor cells, can eventually result in reciprocal tolerance.

\section{SELF NON/SELF DISCRIMINATION}

We have proposed that the principle of immune governance by antigen migration and localization applies to all immune reactions and at all stages of life. ${ }^{7}$ Because the fetus possesses $T$ cell immune function in the very early stages of its development. antigen migration and localization can be viewed as the basis for the ontogeny of self/non-self discrimination during fetal development in the same way as it is for acquired tolerance in later life. Autoimmune diseases would then reflect unacceptable postnatal perturbations of the prenatally established localization of self antigens in non-lymphoid versus lymphoid tissues.

\section{RELEVANCE TO XENOTRANSPLANTATION}

The migration/localization paradigm predicts what will be required to make xenotransplantation feasible. ${ }^{42}$ There is no MHC-restricted safety valve for cytopathic microorganisms that are typically extracellular and generate the full resources of the innate as well as the adaptive immune system. $^{7,10-12}$ This explosive response is provoked by xenografts expressing the Gal- $\alpha$ Gal epitope, an epitope that also is found on numerous bacteria, protozoa, and viruses. Disarming only one of the listed effector mechanisms of innate immunity (Table 1) to prevent hyperacute xenograft rejection (eg, by inserting human complement regulatory genes into pigs) without changing or eliminating the xenogeneic epitope will not allow the clinical use of discordant animal donors.

To avoid the devastating consequences of these effectors, additional genetic manipulation will be required, whereby antigens are eliminated. or equivalent human genes are introduced. Gene knockout procedures have not yet been done in the pig-the animal most commonly targeted as a xenograft donor. However, using molecular technologies, some of which already have been shown to be applicable in pigs, the team of Osman, Sandrin, and McKenzie et $\mathrm{al}^{43}$ in Australia has been able to reduce cell-surface expression of the Gal- $\alpha$ Gal gene product in cultured African green monkey fibroblasts (so called COS cells) to negligible levels. The experiments were staged. As a first step, the COS cells, which normally do not express the Gal- $\alpha$ Gal epitope, were transfected with the Gal cDNA. Because these transfected COS cells now presented a Gal- $\alpha$-Gal target, they were vigorously lysed by the antibodies in human serum (Fig 4).

The anti-Gal lysis was reduced, but not eliminated, by transfection of the altered COS cell with human $\alpha$-galactosidase, which cleaves off $\alpha$-linked galactosyl residues of the target epitope (Fig 5). Because this exposes subterminal saccharides (ie, $\mathrm{N}$-acetyl lactosamine), to which there also are "natural" human antibodies, lysis is only reduced. However, the additional insertion of an $\alpha(1,2)$ fucosyltransferase gene resulted in the substitution of Gal- $\alpha \mathrm{Gal}$ with the nonimmunogenic $\mathrm{H}$ substance (ie, the universally tolerated $\mathrm{O}$ blood group antigen). Thus, the double transfec-

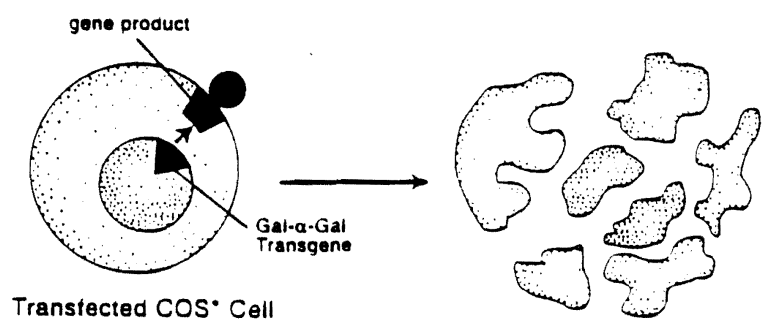

Lysed by human serum

- Alrican green monkey fibroblast

Fig 4. COS cells are lysed by human serum after their transfection with the Gal- $\alpha(1,3) \mathrm{Gal}$ gene (see text). (By permission of J Am Coll Surg, 186:383, 1998) 


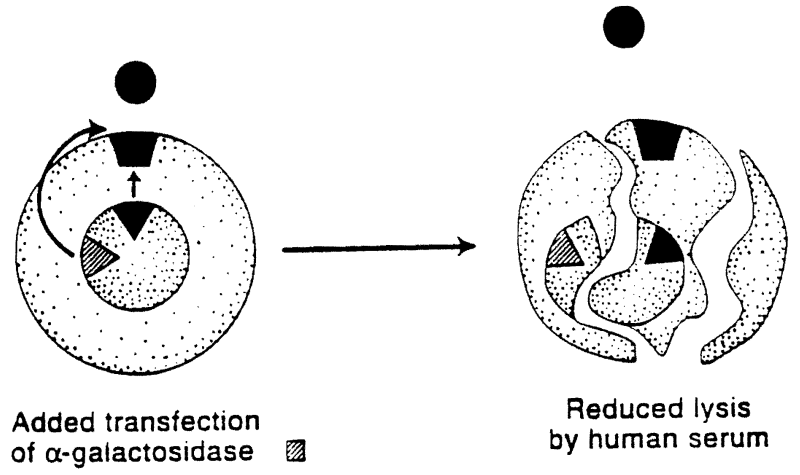

Fig 5. Insertion of $\alpha$-galactosidase gene diminishes, but does not eliminate, the lysis shown in Fig 1 (see text). (By permission of J Am Coll Surg, 186:383, 1998)

tion (galactosidase plus fucosyltransferase) completely eliminated complement-mediated lysis of the COS cells (Fig 6).

The $\alpha$-galactosidase gene has not yet been transfected in pigs, but this has been accomplished with the $\alpha$-fucosyltransferase gene by John Logan and associates of the Nextran Corporation in collaboration with colleagues at Duke University. ${ }^{44}$ Stable double transfection in pigs would seem to be only a matter of time. Thus, far from being bleak, the future of xenotransplantation is brighter than at any previous time because what must be done to succeed has become remarkably clear.

Rules must be followed that have been established by coevolution of the host-parasite relationship. We have already learned empirically with allotransplantation how to work around, or, more accurately, work with, the defense mechanisms developed by nature to control noncytopathic infections. These strategies will not work for xenografts whose antigens are recognized by the immune system as cytopathic microorganisms. Alteration of animal antigens so the organs resemble the less threatening noncytopathic pathogens will be the key to success.

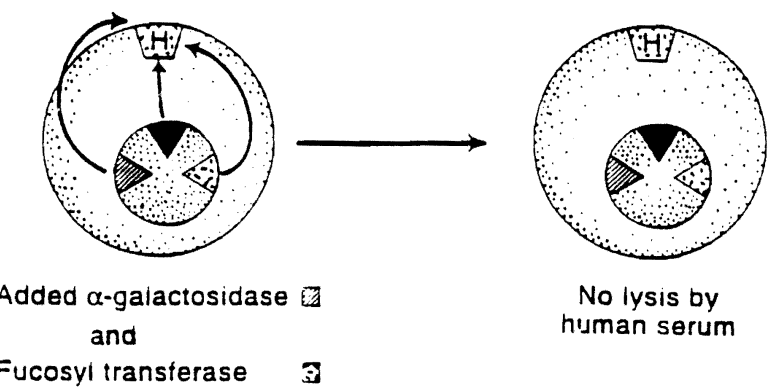

Fig 6. Additional insertion of the $\alpha(1,2)$ fucocyl transferase gene converts the xenogeneic $\mathrm{Gal}-\alpha(1,3) \mathrm{Gal}$ antigen to the $H(\mathrm{O}$, or universal donor) antigen and eliminates lysis (see text). (By permission of J Am Coll Surg, 186:383. 1998)

\section{REFERENCES}

1. Billingham RE. Brent L. Medawar PB: Nature 172:603. 1953

2. Mathe G. Amiel JL. Schwarzenberg L, et al: Brit Med J 2:1633. 1963

3. Bach FH. Albertini RJ. Joo P, et al: Lancet 2:1364, 1968

4. Gatti RA. Meuwissen HJ. Allen HD. et al: Lancet 2:1366. 1968

5. Thomas ED: In Terasaki PI (ed): History of Transplantation: Thirty-Five Recollections Los Angeles, Calif: UCLA Tissue Typing Laboratory; 1991, p 379

6. Starzl TE. Demetris AJ, Murase N, et al: Lancet 339:1579, 1992

7. Starzl TE. Zinkernagel RM: New Engl J Med 339:1905, 1998

8. Starzl TE, Demetris AJ. Trucco M, et al: Hepatology 17:1127. 1993

9. Starzl TE, Demetris AJ, Trucco M, et al: $N$ Engl $J$ Med 328:745, 1993

10. Zinkernagel RM: Science 271:173, 1996

11. Zinkernagel RM, Bachmann MF, Kundig TM, et al: Annu Rev Immunol 14:333, 1996

12. Zinkernagel RM. Ehl S, Aichele P, et al: Immunol Rev 156:199. 1997

13. Starzl TE. Demetris AJ. Trucco M. et al: Transplantation 55:1272. 1993

14. Iwaki Y, Starzl TE, Yagihashi A. et al: Lancet 337:818, 1991

15. Murase N. Demetris AJ, Matsuzaki T, et al: Surgery 110:87, 1991

16. Starzl TE. Marchioro TL. Waddell WR: Surg Gynecol Obstet 117:385, 1963

17. Starzl TE. Marchioro TL. Porter KA, et al: Surgery 58:131. 1965

18. Starz] TE. Demetris AJ, Murase N, et al: Immunol Today 17:577, 1996

19. Lawrence HS: Physiological Reviews 39:811, 1959

20. Doherty PC. Zinkernagel RM: Lancet i:1406, 1975

21. Zinkernagel RM. Doherty PC: Immunol Today 18:14. 1997

22. Starzl TE: Experience in Hepatic Transplantation. Philadelphia: Saunders: 1969, p 229

23. Schwartz R. Damashek W: Nature 183:1682. 1959

24. Webb S. Morris C. Sprent J: Ccll 63:1249, 1990

25. Bishop AG. Sun J. Sheil AGR. ct al: Transplantation 64:1377. 1997

26. Qian S. Lu L. Fu F. ct al: J Immunol 158:4654. 1997

27. Effros RB, Pawelec G: Immunol Today 18:450, 1997

28. Miller JF, Morahan G: Annu Rev Immunol 10:51, 1992

29. Steinmuller D: Science 158:127, 1967

30. Elkins WL. Guttmann RD: Science 159:1250, 1969

31. Cohn M: Annu Rev Immunology 12:1. 1994

32. Nemlander A. Soots A. Willebrand EV, et al: J Exp Med 156:1087. 1992

33. Larsen CP. Morris PJ. Austvn JM: J Exp Med 171:307. 1990

34. Demetris AJ. Murase N. Fujisaki S. et al: Transplant Proc 25:3337. 1993

35. Talmage DW. Dart G. Radovich J. et al: Science 191:385. 1976

36. Laffertv KJ. Prowse SJ. Simeonovic CJ: Annu Rev Immunol 1:143. 1983

37. Ohashi PS. Oehen S. Buerki K. et al: Cell 65:305. 1991

38. Ohashi PS. Oehen S. Aichele P. et al: J Immunol 150:5185. 1993

39. Wood K. Sachs DH: Immunol Today 17:584. 1996 
40. Starzl TE. Murase N, Demetris AJ. et al: Transplantation 62:703, 1996

41. Starzl TE. Demetris AJ: JAMA 273:876, 1995

42. Starzl TE. Rao AS, Murase N. et al: J Am Coll Surg 186:383, 1998
43. Osman N, McKenzie IFC, Ostenried K et al: PNAS 94: 14677, 1997

44. Sharma A. Okabe J, Birch P. et al: Proc Natl Acad Sci USA 93:7190. 1996 